\title{
Research of Modern Information Technology on Tree Growth Management Decision Making Model
}

\author{
Yuan Li,Wenqing Zhang,Hua Liu,Huiqin Yang,Xuning Liu \\ Department of Computer, \\ Shijiazhuang University \\ Shijiazhuang, China \\ E-mail:sjzhei@163.com
}

\begin{abstract}
Tree growth management decision-making model can simulate growth management of tree and perform quantitative analysis of tree growth conditions. This paper explores the feasibility of modern information technology in management assessment of tree growth, information technology include neural network, ontology and expert system technology, then ontology technology is used to establish ontology database and knowledge base of tree growth management resource, the growth simulation and tree growth management ontology technology are used to build simulation models of tree growth, then expert systems and neural network technology are combined to simulate tree growth development process of decision-making model. The practice has proved that the research can not only predict the growth conditions of tree and dynamic grasp the growth process of the tree, but also can provide theoretical basis for the analysis and evaluation of tree growth management, greatly improving the level of tree growth management.
\end{abstract}

Keywords-ontology;neural expert system; growth management; decision model

\section{INTRODUCTION}

Although the basic research of tree growth management based on simulation model has done a lot of work, because the trees have the characters that growth cycle is long, morphological structure is complex and it is difficult to control environmental conditions, making that the study of tree growth management decision making model is more complex[1]. Management model for tree growth at home and abroad is mainly the basic research, but the research is still not deep enough and system, the decision making model of tree growth management based on modern information technology has important theoretical significance and application value.

The paper presents the expression of ontology knowledge of tree growth management resources, builds tree growth management resources ontology database and ontology knowledge base, the tree modeling technologies are used to perform dynamic simulation of tree growth under a variety of natural conditions, then establish simulation models of tree growth management resource, achieve data access technology of tree growth management resources and establishment of management decision-making model of tree growth using neural networks and expert systems. This paper possibly creates management decision making models and directs the process of tree growth in all aspects of tree growth through the integration of modern information technologies, improves the accuracy of the model simulation, predictive capability and expert reasoning ability of the model, provides evaluation and selection of management mode and management measures for tree growth management, which has practical significance for the scientific management and decision making of tree growth[2].

\section{RELATED RESEARCH}

\section{A. Ontology}

Ontology is scientific methodology that computer language is used to normalize knowledge representation, perform knowledge organization and carry out knowledge services. Theories, techniques and methods of ontology are used to carry out data representation for tree management resources, which have caused widespread concern at home and abroad and become academic research frontier and hot. Many aspects of tree growth management resources in the field of data, database, knowledge base and ontology construction principles, methods, and representation do not form unified standard, tree growth management resource in the field of data standardization is very low, the degree of standardization of agricultural units of measurement, agricultural jargon in the information processing in accordance with the corresponding standard synonym and homonym phenomena are very serious, resulting in data dead ends, and even making junk information, information resources are many, and are lack of diversity in multimedia information and full text are less, the degree of openness and sharing of information retrieval and navigation system are unreasonable and inefficient[3].

Tree growth and management resource name requires unified necessary standardization, then the problem will be solved through the establishment of tree growth and management of domain ontology semantic lexicon ontology library; Considering the national industrial and agricultural product classification standard (GB7653-87) and standard International Trade (SITC) under the premise of the study and formulation of standards for classification of tree growth and management parameters. The ontology database of tree growth management are built, then the parameters of the tree growth management are used for ontology representation and are stored for the database, then provide information for the research of tree growth development model; The research of 
knowledge base technology based on ontology contribute to build domain ontology knowledge base of tree growth and management, achieving normalization and standardization of tree growth management resources decisions ontology, providing favorable conditions for the industry and building shared knowledge reasoning mechanism, supplying users with intelligent decision support management resources for tree growth model library[4].

\section{B. Neural Expert System}

The neural expert system is hybrid systems that combine the advantages of expert system and neural network, which is much more powerful than single one in the ability, stability and parallel processing. The neural network technology is used for data acquisition, and expert system is used for expert reasoning. Neural network and expert system are used to achieve the prediction of trees growth management, the research of the tree growth management decision-making model can make use of prediction ability of neural network simulation model and decision-making role of the expert system[5].

The neural networks is used for knowledge acquisition, first we need study all kinds of neural network models, then establish the non-linear relationship of tree growth management and management parameters, dynamic simulate tree growth management situation using non-linear and complex construction modeling technology, establish the good nonlinear predictive model of tree growth management. The models that are built between tree growth management and various parameters that affect tree growth management model using neural network modeling technology are used to conduct comprehensive study; Expert system is used for expert reasoning and judgment, and study how to collect, summarize and analyze the experience and knowledge of the field of expert, analyze expert system knowledge, as well as the reasoning mechanism, and make full use of the characters of the expert system reasoning.

The expert system and neural networks technology are combined, then experience and knowledge of the experts in the field of tree growth model reasoning decision-making is made, the forecasting of neural network model and logical reasoning system of expert system are combined. The integrated reasoning based on user input parameters factor, forecast, interpretation and other mechanisms can help users design tree growth management program, answer the problem of management techniques and the dynamic regulation trees fertility process, and can accurately predict the trees at various stages of growth conditions and yield, achieve precision control and quantitative management objectives of environment and tree growth and development[6].

\section{Growth Modeling Techniques}

The link between tree growth model and influencing factors requires mining, and the plant growth simulation models are improved. According to the data in tree growth management domain ontology database, the tree modeling techniques are used to build the tree growth simulation model library. The forms need integrated learning $\mathrm{L}$ system fractal method, iterated function systems, branching matrix, particle system, the reference axis technology at home and abroad, and so plant modeling technology, the application of systems analysis and computer models, such as the various improvements technology, ecology, computer-disciplinary research, tree physiology, morphology, environmental impact three dynamic quantitative analysis and growth simulation model as a whole, using computer modeling to simulate trees of growth process, improving the accuracy of the simulation of the tree growth process.

Considering environmental factors, the simulation of the process of tree growth is made using data in the field of tree growth management ontology database, the tree growth management and related factors that affect tree growth management growth model are made, these models quickly and accurately contribute to obtain and analyze a variety of information of the state of tree growth and the environment. The repository of tree growth model is built under different conditions, lay foundation for growth management decisionmaking model based on the knowledge base of the tree growth model and management.

\section{CONSTRUCTION OF TREE GROWTH MANAGEMENT DECISION MODEL}

\section{A. Ontology Representation of Tree Growth Management Resources}

Because domain knowledge of tree growth management includes resources information and management measures, and decision-making elements, which can be divided into tree growth resource information and management decisionmaking resource information. Ontology technology can provide shared conceptualization of the specification for tree growth management resource information, and this specification is described in formal way, making users and computers share and reuse domain knowledge in structure way.

The construction of tree growth management domain ontology database and knowledge base are base of implementation of decision-making model, In this study, we propose the combination of skeleton method which can build the ontology and the seven-step which can use domain ontology to build ontology database and knowledge base, adopt RDF to describe tree growth management knowledge metadata model, and use the ontology editing tools to create metadata RDF data documentation, and Jena tools are used to achieve expression of RDF data parsing, query and simple reasoning, enabling trees growth management areas of ontology representation; According to concept set, attribute set, the set of instances, the axiom set four sets, knowledge model are used to describe, improve the accuracy and sharing of tree growth management knowledge representation, analyze of the characters of the relationship between tree growth management domain knowledge, the method is constructed by the set of tree growth management concept, attribute set, the set of instances, and a set of axioms trees community growth on tree growth management knowledge model body, at last the owl ontology is used to 
store ontology, and provide services to support tree growth simulation model knowledge.

\section{B. Growth Model of Tree}

After the ontology database of tree growth management and visualization reference model are built, the simulation model of tree growth management is constructed, and perform effective organization and processing on data that are obtained by the simulation models of trees growth, the processing of data are converted to graphics information through graphical algorithms, the tree growth model library of various developmental stages are built. Tree growth simulation mainly presents qualitative observations of different growth conditions, and different growth stages of trees, judge growth mode, determine the overall framework of the morphology of description, measure the quantitative determination of tree topology, geometry, mechanical properties, extract rules morphology model of the trees, simulate tree growth based on growth rules, and the establishment of tree growth model based on a variety of competitive factors. During the course of growth process, the user can provide environment parameters and tree growth parameters and as input parameters of tree growth model. After physiological and ecological model calculates, we can simulate tree growth conditions, the visualization model is available to the user.

\section{Decision Making Model of Tree Growth Management}

Growth management decision-making model is based on growth management domain ontology knowledge base and tree growth model base of trees, neural network technology is used for data acquisition of tree growth management domain ontology knowledge base, and expert system is used for expert reasoning. Hybrid systems that combine the advantages of expert system and neural network is called neural expert system, and the learning ability, summarized ability, stability and parallel processing capabilities are much more powerful than single one. The neural network is regarded as the input of the expert system, and the expert system is used to analyze the results of the neural network, neural network learning training results are closer to the actual tree growth management situation, the realization of the model has the function of the fuzzy inference diagnostic ability. The neural networks, expert systems technology, tree growth management resource model library and knowledge base contribute to simulate the dynamic growth of the trees in the breed type, production conditions and growth state forecasting different ecological environment, and implementing management decisions based on simulation results.

\section{ANALYSIS}

Ontology theory and database technology are combined to establish domain ontology database and knowledge base of tree growth management, ontology theory is applied to the tree growth management knowledge, and is the specific application of the ontology, the standardization of naming is made, and tree growth management domain ontology database and knowledge base are constructed, we can get more parameters than the traditional methods, and study tree growth management model. After all kinds of modeling techniques are studied, ontology database expands the meaning of tree growth modeling ontology database, analyzes the relationship between research of tree growth management model and the impact factor using ontology base, improving resource utilization and simulation effects, and is a very important for the trees growth simulation model, and the analysis is the first at home and abroad. The neural networks and expert systems technology are applied in the construction of decision-making model of tree growth based on model base and knowledge base of tree growth management, and the neural networks and expert systems are combined to achieve the establishment of the knowledge base of the trees based on tree growth model base and growth management ontology.

The tree growth management model based on modern information technology integration structure have characters such as components, integration and intelligence, plant growth modeling and modern information technology are used, through the study of the paper we can likely get the new results of tree growth model research of modern information technology, which can provide new theories, new techniques and new tools for intelligent simulation of tree growth management, so direct the growth management work of tree.

\section{CONCLUSION}

The paper performs depth study on tree growth simulation model, and the integrated use of tree growth simulation model technology, the ontological techniques, neural networks and expert systems technology are used to establish tree growth management decision model, then tree growth management resources data can form unified platform for the sharing, fully considering the various factors that affect tree growth management and the degree of standardization of data, make integrated growth simulation model and the analysis and evaluation system, so generate dynamic and intelligent decision-making information which are applicable to the different experimental designs.

Various methods of plant modeling require improvement, so we need continue to improve the integration of multidisciplinary knowledge, use consolidated various to achieve the integration of modern information technology and a variety of plant modeling method, and take full account of the interaction between the trees and the environment on tree growth, which has significance in management decision of tree.

\section{ACKNOWLEDGMENT}

We are very grateful to Professor Li Ping for his kind assistance. And we also thank for the great support from China Agricultural University.

\section{REFERENCES}

[1] Song B, Wang XL,"Visualizing a landscape,its changes and driving processes,"Nova Science Publishers,Incorporation,vol3,pp.167-190, 2006. 
[2] Sheppard SRJ,Meitner M,”Using multi-variables analysis and visualization for sustainable forest management planning with stakeholder groups,’Forest Ecology and Management,vol207,pp.171187,2005 .

[3] Meitner MJ,Sheppard SRJ,Cavens D,eta1,”The multiple roles of environmental data visualization in evaluating alternative forest management strategies," Computers and Electronics in Agriculture, vol49,pp.192-205, 2005.
[4] Song B,David J,"Forest visualization at multiple scales for management and planning," Series Technological Sciences,vol49,pp.27-34, 2006.

[5] Falcao AO,Santos M P D,Borges J G,"A real-time visual tool for forest ecosystem management decision support,"Computers and Electronics in Agriculture,vol53,pp.3-12, 2006.

[6] Stohman AM,Radel of VC,Mladen of DJ,"Computer visualization of presettlement and current forests in Wisconsin,"Forest Ecology and Management,vol246,pp.135-143,2007. 